\title{
Tailings storage facilities store-and-release cover design for the Cobar region
}

\author{
NP Jamson SGM Environmental Pty Ltd, Australia \\ TK Rohde SGM Environmental Pty Ltd, Australia
}

\begin{abstract}
The Cobar region (the region) is located approximately $700 \mathrm{~km}$ west of Sydney in central western New South Wales (NSW). The region has a semi-arid climate with low humidity, low rainfall and high evaporation. Annual rainfall is approximately $400 \mathrm{~mm}$ while evaporation averages 2,000 mm annually. The Cobar basin is one of the most significant metalliferous regions in Australia, containing extensive base and precious metal deposits. The typical large, high-grade deposits of the region are hosted by marine sediments and consist of multiple lenses in steeply plunging, pipe-like clusters. There are currently five operational mines in the region that mine a range of metals including copper, lead, zinc, silver and gold. During ore processing, potentially acid forming (PAF) tailings are generated and discharged underground or to tailings storage facilities (TSF). PAF tailings require careful rehabilitation to minimise the risk of harm to the receiving environment.

Typically, the rehabilitation of a TSF involves two controls. First, controlling the potential for PAF tailings to form acid mine drainage (AMD) by limiting interaction with oxygen that promotes oxidation of sulphides to form $A M D$. Second, once the tailings are unsaturated, limiting interaction with water to reduce the potential for AMD to be transported to the receiving environment. These two forms of control are often employed in the form of a cover.

In semi-arid environments, there are many Australian examples of covers that have been built to limit interactions of tailings with oxygen and water. Typically, the covers contain two or more layers and are built from soil and rock that may include run-of-mine waste rock.

The purpose of this paper is three-fold and describes the cover design process employed by two mines (Mine $A$ and Mine $B$ ) in the region (the mines). That is, the paper describes the desktop cover design process that the mines used to develop cover options for the TSFs. Secondly, the paper describes the method and results of large column trials that were used as a cost-effective way to trial multiple cover options for the TSFs. Finally, the paper describes the cover design models that were built from the column trial results and how the models were used to scale up and assess the potential future performance of the covers if they were built on the TSFs. From this data, suitable cover designs for TSFs in the region will be identified.
\end{abstract}

Keywords: mine closure, tailings storage facilities, TSF, cover design, Cobar

\section{Introduction}

The Cobar region (the region) is located approximately $700 \mathrm{~km}$ west of Sydney in central western NSW. The region extends from approximately $30 \mathrm{~km}$ northwest of Cobar to approximately $100 \mathrm{~km}$ southeast of Cobar. The topography of the region is typically flat or gently undulating dotted with stony ridges and ranges. A large portion of the region is rangeland where vegetation consists of poplar box woodlands, mulga communities and cypress pine.

The region is one of the most significant metalliferous areas in Australia, containing extensive base and precious metal deposits. The region has been a significant source of mineral wealth for 140 years since the discovery of the Great Cobar copper deposit in 1870. Mine A mines zinc ( $\mathrm{Zn})$, lead $(\mathrm{Pb})$ and silver $(\mathrm{Ag})$, while Mine $\mathrm{B}$ mines gold ( $\mathrm{AU}), \mathrm{Pb}$ and $\mathrm{Zn}$. Both Mine $\mathrm{A}$ and Mine $\mathrm{B}$ are underground mines that are accessed through an initial box cut, portal and decline. 
During ore processing, PAF tailings are generated and discharged underground or to a TSF. At both mines PAF tailings contain sulphides, which when exposed to oxygen and water form AMD. The PAF tailings require careful management to minimise the risk of harm to the receiving environment. A gap analysis of Mine $A$ and Mine $B$ in, identified that a cover was required to limit the potential for rainfall percolation into tailings and for AMD to be transported. Limiting percolation will decrease the potential for seepage and the potential impact on the receiving environment. In semi-arid environments such as the region, there are many Australian examples of covers that have been built to limit interactions of tailings with oxygen and water.

\subsection{Regional geology}

The region's geology is characterised by siliciclastic sediments locally intruded with felsic volcanics. The region has large, high-grade deposits that are hosted by marine sediments and consist of multiple lenses in steeply plunging, pipe-like clusters.

\subsection{Regional soils}

Soils in the region are relatively uniform and relate closely to topographic position and local geology. The steeper slopes, ridges and crests tend to have sandy to earthy tenosols. The tenosols gradually grade down into red dermosols, kandosols and calcarosols on the lower slopes, lowlands and flats with several variants existing. Deep alluvial and sandy soils commonly occur in the channels and creeks.

\subsection{Land use}

The predominant land uses in the region are agriculture and mining. Agriculture in the region is mainly sheep grazing and some cattle grazing. There are currently five operational mines in the region that mine a range of metals including copper ( $\mathrm{Cu}), \mathrm{Pb}, \mathrm{Zn}, \mathrm{Ag}$ and $\mathrm{AU}$.

\section{Review}

\subsection{Climate and cover type}

Among other factors, climate is an important element in determining the type of cover most suited to TSFs in the region (International Network for Acid Prevention [INAP] 2009). The climate of the region is semi-arid with low humidity, low rainfall and high evaporation. Annual average rainfall is approximately $400 \mathrm{~mm}$ and is typically evenly distributed throughout the year. Rainfall is exceeded by evaporation and averages approximately $2,000 \mathrm{~mm} /$ year. The combined effect of evaporation and transpiration (evapotranspiration) at the mines is five times greater than rainfall. The GARD guide (INAP 2009) suggests that a store-and-release cover (the cover) might be an effective tool, in combination with other safe guards (i.e. a capillary break or a reduced permeability layer ( $R P L)$ ) to reduce the potential for environmental harm from TSFs after mine closure (Figure 1).

\section{$2.2 \quad$ Mine A}

\subsubsection{Tailings geochemistry}

Tailings in the Mine A TSF have a very high sulphide content in the range of $10-35.5 \%$. The tailings have minimal acid neutralising capacity (ANC), ranging between $0-5 \mathrm{~kg} \mathrm{H}_{2} \mathrm{SO}_{4} / \mathrm{t}$. Net acid production potential (NAPP) is very high and ranges between approximately $500-1,100 \mathrm{~kg} \mathrm{H}_{2} \mathrm{SO}_{4} / \mathrm{t}$. Elevated total metals in the tailings include arsenic (As) (approximately 580-3,500 milligrams per kilogram (mg/kg)), Pb (approximately 980-2,400 mg/kg), Cu (approximately $40-1,400 \mathrm{mg} / \mathrm{kg}$ ) and $\mathrm{Zn}$ (approximately 5,470-12,600 mg/kg). Elevated levels of water-soluble aluminium (Al) $(<0.2-216 \mathrm{mg} / \mathrm{kg})$, cadmium (Cd) $(0.1-4.4 \mathrm{mg} / \mathrm{kg}), \mathrm{Cu}$ $(0.03-131 \mathrm{mg} / \mathrm{kg}), \mathrm{Pb}(0.14-4.1 \mathrm{mg} / \mathrm{kg})$, iron $(\mathrm{Fe})(43-2,080 \mathrm{mg} / \mathrm{kg})$, manganese $(\mathrm{Mn})(8.8-150 \mathrm{mg} / \mathrm{kg})$ and $\mathrm{Zn}(25-1,590 \mathrm{mg} / \mathrm{kg})$ indicate that these metals may be easily leached in surface runoff or seepage. 


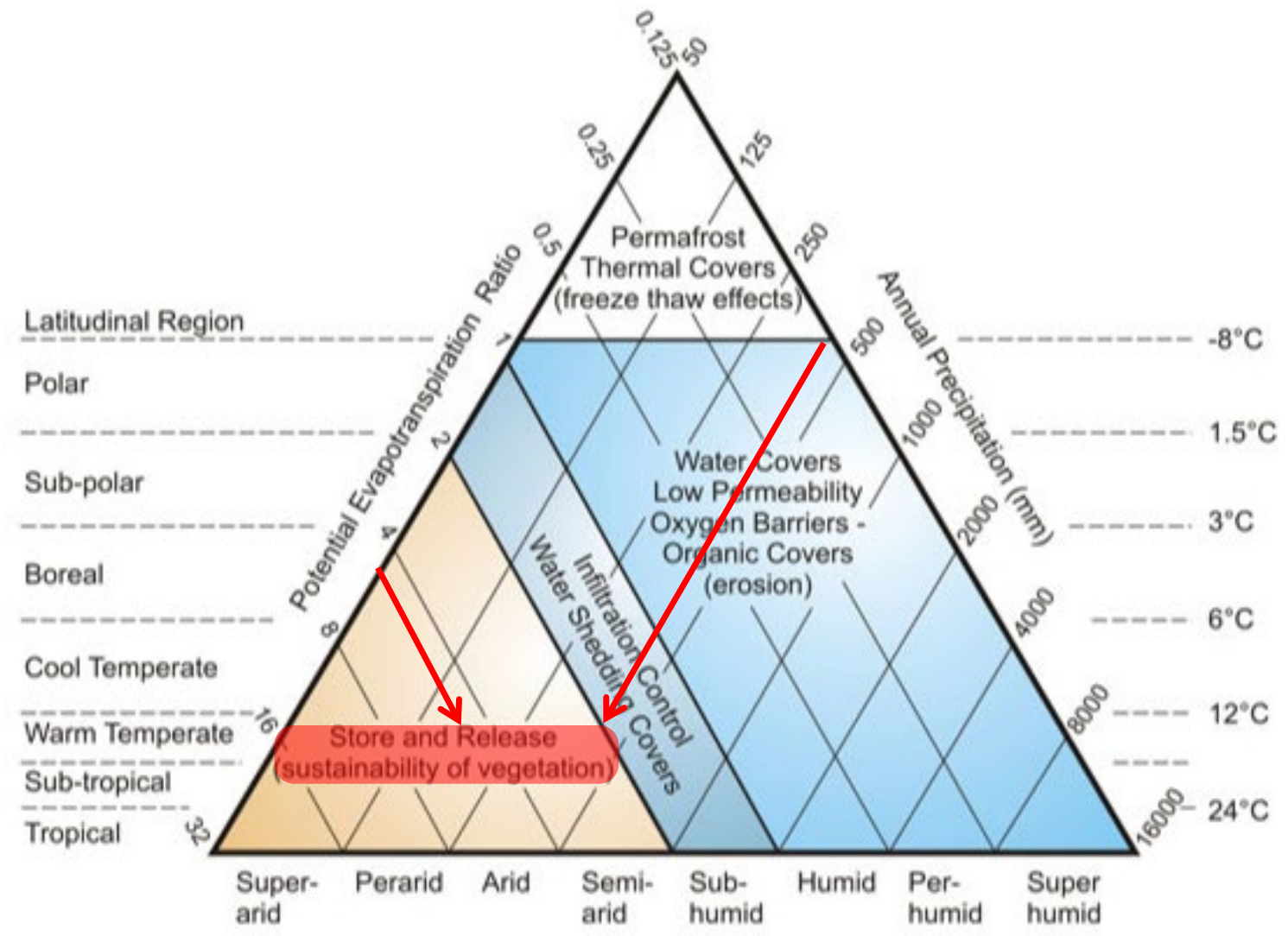

Figure 1 Covers and climate types (INAP 2009)

\subsubsection{Soil and accretion physical and chemical properties}

Soils at Mine A are predominantly red dermosols, kandosols and tenosols. The soils tend to have very little organic matter with a circum-neutral pH down the profile. Other than the higher organic matter content in the topsoil, soils are poorly differentiated and massive. Soil texture is usually sandy clay loam to clay loam in the topsoil and sandy clay to clay in the subsoil. Soils tend to have a high gravel content. The majority of soils at Mine $\mathrm{A}$ have a low dispersion risk under normal conditions but may disperse when disturbed.

Mine A has a limited supply of stockpiled soil available for TSF rehabilitation. Waster rock is also not generated in large quantities at Mine $A$ and is backfilled underground. Soil, rock and ore accretion (accretion) beneath the mine industrial area (i.e. infrastructure area used for processing and handling ore) (MIA) was identified as a potential source of borrow material for the TSF cover. The advantage of this strategy is that any potential contamination will be removed from the MIA. An analysis of total metals showed that $\mathrm{As}, \mathrm{Cu}$, $\mathrm{Zn}$ and $\mathrm{Pb}$ are all enriched with some samples having $\mathrm{As}$ and $\mathrm{Pb}$ above National Environmental Protection Measure 2013 (National Environment Protection Council 2013) health investigation levels C (public open space and recreational areas). These enrichments are similar to those observed in undisturbed soil and rock samples suggesting that accretion may be suitable for use in covers at Mine A. Accretion texture varies from sandy loam to sandy clay. The majority of accretion samples have a low dispersion risk. Median particle size distributions (PSDs) of soil and accretion at Mine A are shown in Figure 2. 


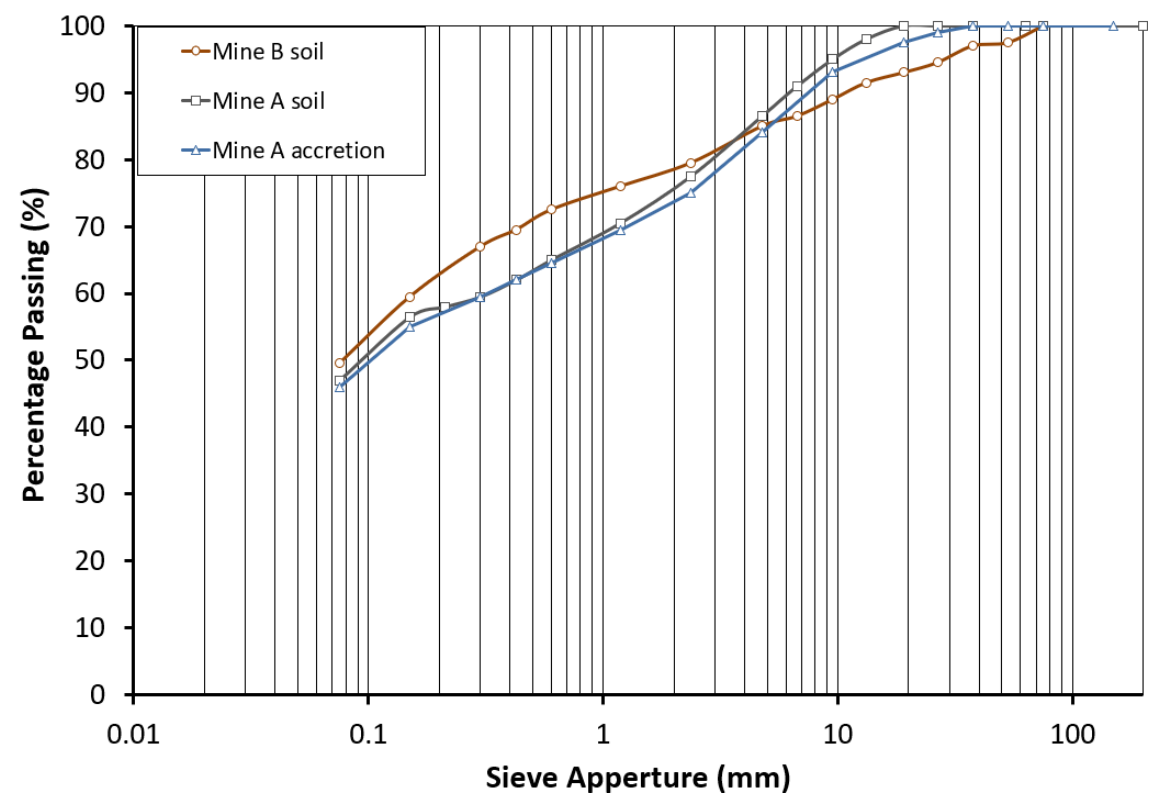

Figure 2 Median particle size distribution of cover materials at Mine A and Mine B

\subsection{Mine B}

\subsubsection{Tailings geochemistry}

Tailings in the Mine B TSF have a high sulphide content in the range of 1.1-10.9\%. ANC is generally low, ranging between $1.3-11 \mathrm{~kg} \mathrm{H}_{2} \mathrm{SO}_{4} / \mathrm{t}$. NAPP is moderate to very high and ranges between $29-326 \mathrm{~kg} \mathrm{H}_{2} \mathrm{SO}_{4} / \mathrm{t}$ (noting that one sample had a NAPP of $-1 \mathrm{~kg} \mathrm{H}_{2} \mathrm{SO}_{4} / \mathrm{t}$ ). Elevated levels of water-soluble Al $(<0.2-35 \mathrm{mg} / \mathrm{kg}$ ), $\mathrm{Cd} \quad(<0.01-6.1 \mathrm{mg} / \mathrm{kg}), \quad \mathrm{Fe} \quad(<0.2-960 \mathrm{mg} / \mathrm{kg}), \quad \mathrm{Pb} \quad(<0.2-34 \mathrm{mg} / \mathrm{kg}), \quad \mathrm{Mn} \quad(1.8-90 \mathrm{mg} / \mathrm{kg})$, nickel (Ni) $(<0.05-12 \mathrm{mg} / \mathrm{kg})$ and $\mathrm{Zn}(0.2-2,400 \mathrm{mg} / \mathrm{kg})$ indicate that these metals may be easily leached in surface runoff or seepage. Total metals data in not available. Aged, oxidised tailings tended to have an extremely acidic $\mathrm{pH}$, high water-soluble sulphates and a high electrical conductivity (EC). Fresh tailings at Mine B's TSF have a very acidic $\mathrm{pH}$, high reactive sulphides and lower water-soluble metals than the oxidised zone.

\subsubsection{Soil physical and chemical properties}

Soils at Mine B are predominantly red kandosols and dermosols. The soils tend to have very little organic matter with a variable $\mathrm{pH}$. Cation exchange capacity is low to moderate. Organic matter content is low with weak to moderate structure. Soil texture is usually in the range of sandy clay loam to sandy clay. The soils have a high gravel content that increases down the profile. The majority of soils at Mine B have a low dispersion potential under normal and disturbed conditions but further breakdown may occur by water turbulence or concentrated rapid water flow. The median PSD of soil at Mine B is shown in Figure 2. Note the similarity to the soil and accretion at Mine A.

\section{Methodology}

The following method statement describes the approach used by the mines to develop the future covers for the TSFs.

It was decided that the mines would establish cover trials to determine the future cover for the TSFs. The purpose of this approach was to provide enough in situ data for volumetric water content, matric suction, seepage and weather to develop a maximum probable water balance that could be used in a desktop model such as SVFlux to decide on a final future cover thickness. It is not the sole purpose of this approach to validate any particular trialled configuration-albeit, that it is accepted that this may also be an outcome of the approach. 


\subsection{Column cover trials}

The low rainfall environment was seen as a limiting factor to achieving a timely response from potential cover trials. Since regional experience would indicate that several years of data would be required to capture a representative window of how the cover responds to seasonal changes. In order to achieve interim data of cover performance, it was decided that the cover trials would be constructed as large columns.

\subsubsection{Mine A}

The covers at Mine A were trialled in $2 \mathrm{~m}$ tall columns with a surface area of $0.25 \mathrm{~m}^{2}$. The base is perforated to allow percolation to pass out of the column. The following covers were trialled at Mine A (Figure 3):

- $0.45 \mathrm{~m}$ cover made up of a $0.3 \mathrm{~m}$ RPL of accretion overlain by a $0.15 \mathrm{~m}$ infiltration storage layer of soil.

- $0.6 \mathrm{~m}$ cover made up of a $0.3 \mathrm{~m}$ RPL of accretion overlain by a $0.3 \mathrm{~m}$ infiltration storage layer of soil.

- $0.8 \mathrm{~m}$ cover made up of a $0.3 \mathrm{~m}$ RPL of accretion overlain by a $0.5 \mathrm{~m}$ infiltration storage layer of soil and accretion.

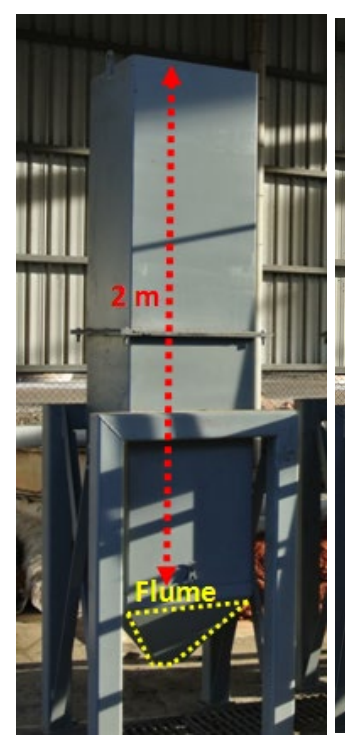

(a)

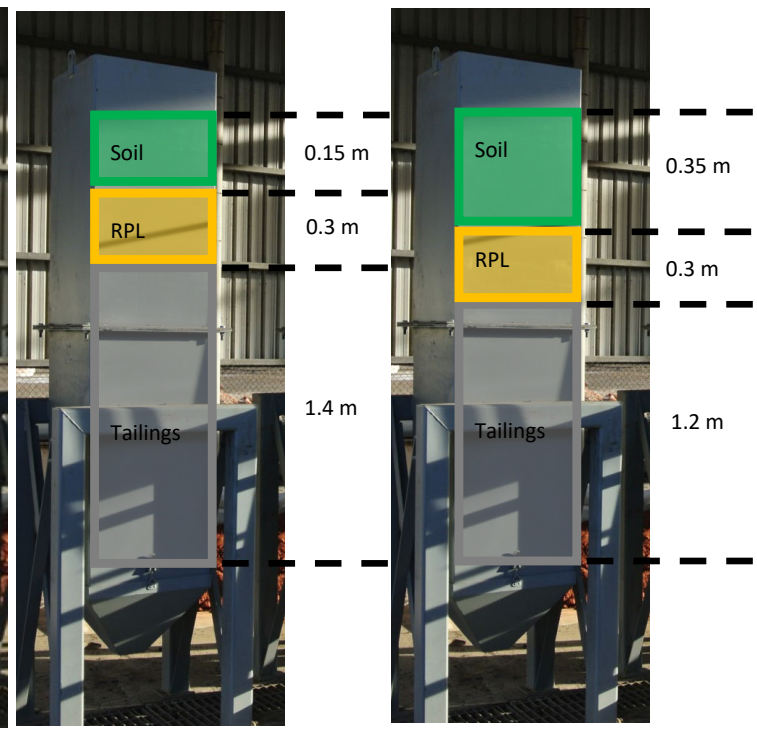

(c)

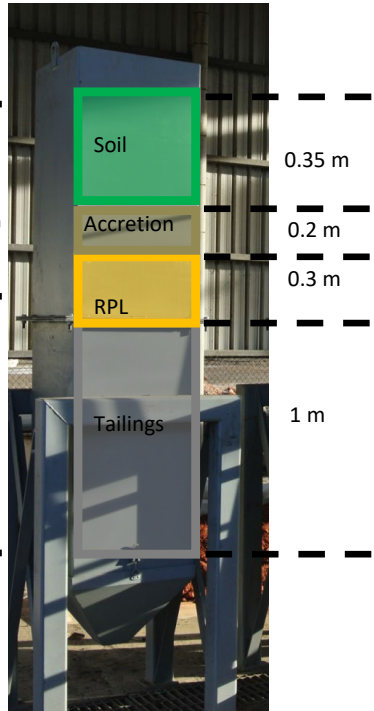

(d)

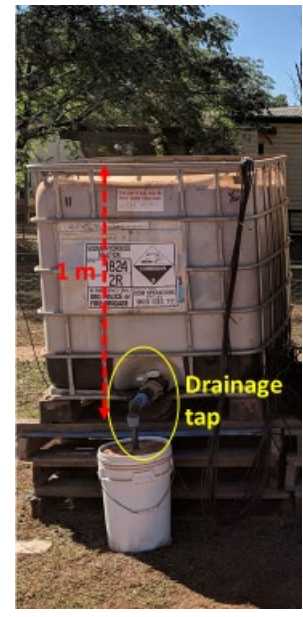

(e)

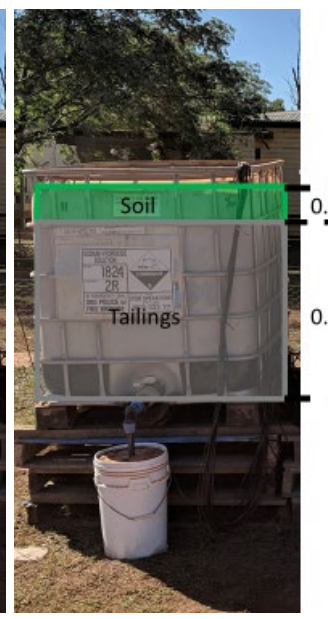

(f)

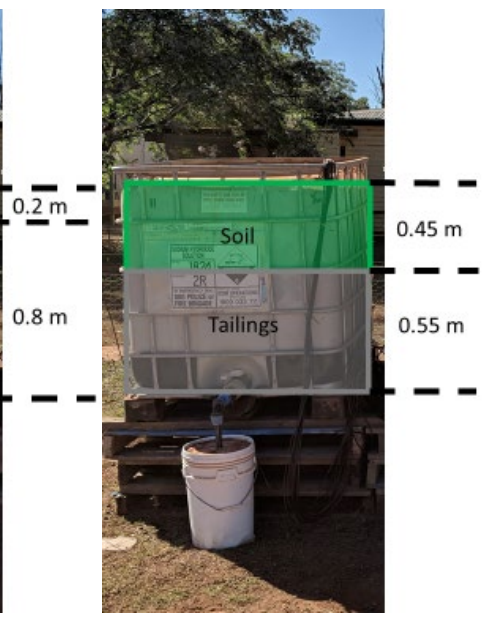

(g)

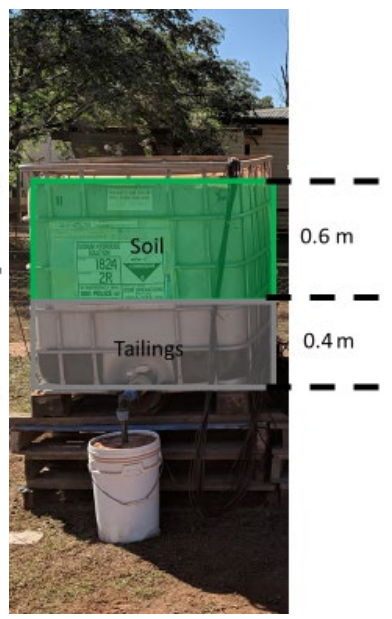

(h)

Figure 3 Column trials: (a) Column components (Mine A); (b) $0.45 \mathrm{~m}$ cover (Mine A); (c) $0.6 \mathrm{~m}$ cover (Mine A); (d) $0.6 \mathrm{~m}$ cover (Mine A); (e) Column components (Mine B); (f) $0.2 \mathrm{~m}$ cover; (g) $0.4 \mathrm{~m}$ cover; (h) $0.6 \mathrm{~m}$ cover 
Covers incorporating accretion were trialled at Mine A due to a limited supply of stockpiled soil. Waste rock is also not generated in large volumes as it is used for backfill underground. The covers were also proposed on the basis that the accretion could only be used to build the RPL or used in the bottom of the soil layer directly above the RPL.

\subsubsection{Mine B}

The covers at Mine B were trialled in intermediate bulk containers (IBC) with a surface area of $1.17 \mathrm{~m}^{2}$. The IBCs were graded so that percolation flows towards a drainage tap. The following covers were trialled at Mine B (Figure 3):

- $0.2 \mathrm{~m}$ cover made up of an infiltration storage layer of soil.

- $0.4 \mathrm{~m}$ cover made up of an infiltration storage layer of soil.

- $0.6 \mathrm{~m}$ cover made up of an infiltration storage layer of soil.

Early modelling at the conceptual design phase indicated that a sufficiently thick cover of soil may not require an RPL. Mine B has an abundance of stockpiled soil; thus, the above covers were chosen for column trials.

\subsection{Instrumentation}

The column trials were instrumented with volumetric water content sensors (also capable of measuring EC) and matric suction sensors to measure how rainfall infiltration and dissolved ions are stored within the cover. At Mine $A$, the sensors were buried so that they were positioned at the upper and lower boundary of the infiltration storage layer and at the upper, middle and bottom of the RPL. At Mine B, the sensors were buried so that they were positioned at the upper, middle and bottom of the infiltration storage layer and the upper and lower boundary of the tailings layer.

Seepage was recorded using rain gauge tipping buckets placed under each individual column and the remaining element of the water balance, evaporation was calculated using Equation 1:

$$
\text { Evaporation }=\text { Artificial rainfall }- \text { seepage }- \text { stored infiltration }
$$

Seepage chemistry is not presented in this paper.

\subsection{Model set-up}

SVFlux was developed by SoilVision (2009) (the model) and uses a finite element mesh that simulates water movement for both saturated and unsaturated conditions. The preferred $0.6 \mathrm{~m}$ cover for Mine $B$ has been modelled. The same modelling process was also completed for the preferred $0.6 \mathrm{~m}$ cover for Mine $A$ but is not presented in this paper, other than a comparison in Section 5.1.2.

The model was developed in one-dimension and calculates the upward and downward movement of rainfall infiltration and seepage. It assumes no surface runoff or run-on and allows ponding at the ground surface. Transpiration from vegetation has been conservatively excluded since data is not available (i.e. only considers evaporation).

\subsubsection{Model dimensions}

The model was developed to replicate the cover column trial一that is, $1 \mathrm{~m}$ thick with $0.4 \mathrm{~m}$ of tailings overlain by $0.6 \mathrm{~m}$ of soil.

\subsubsection{Mesh geometry}

The automatic mesh generation and automatic mesh refinement algorithms were utilised in SVFlux for the $0.6 \mathrm{~m}$ (Mine B) cover. 


\subsubsection{Initial conditions}

\subsubsection{Evaporation}

Potential evaporation in the model was kept at $95 \%$ of rainfall as this was observed in the column trials.

\subsubsection{Soil water characteristic curves}

The models require soil water characteristic curves (SWCC). A SWCC is the relationship between volumetric water content and matric suction for each depth where the sensors are placed in the cover (the in situ results).

The in situ SWCCs for each material were fitted to the in situ results using the Fredlund \& Xing (1994) method (Figure 4). The average trend lines for each material was used in the model.

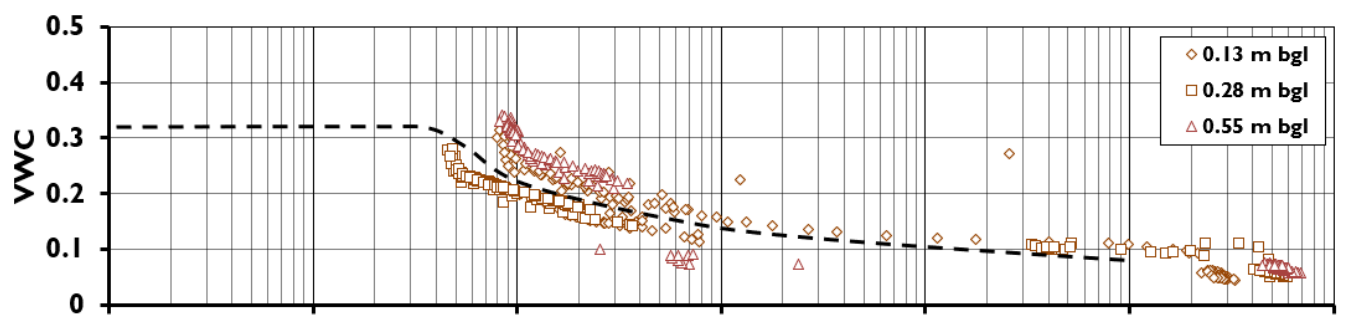

(a)

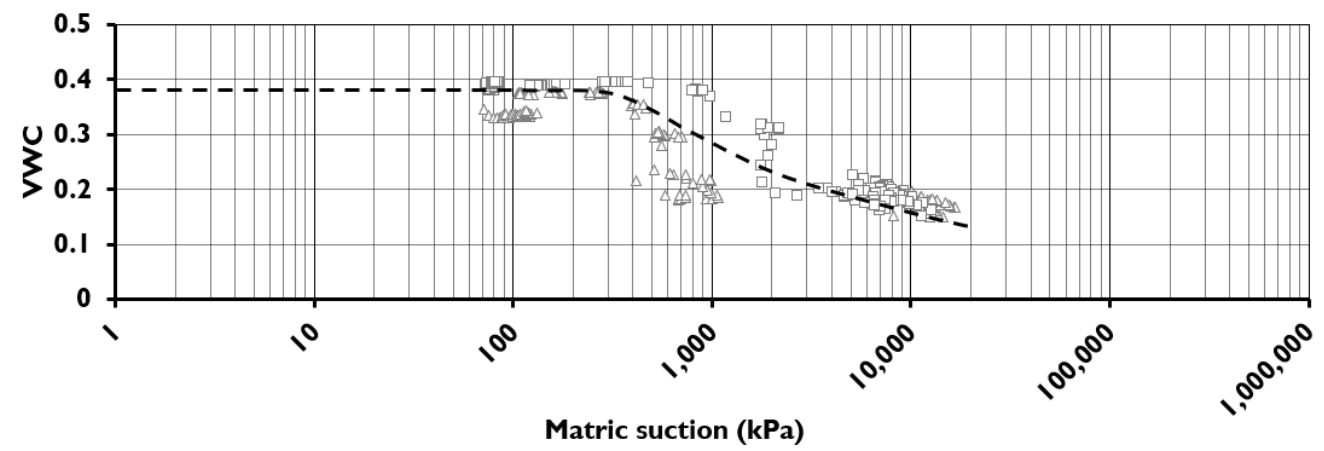

(b)

Figure 4 Soil water characteristic curves for the $0.6 \mathrm{~m}$ (Mine B) cover: (a) the soil cover; (b) the tailings layer

\section{$4 \quad$ Results}

\subsection{Artificial rainfall}

\subsubsection{Mine A}

The column trials at Mine A were subjected to 14 artificial rainfall events over approximately nine months:

- Seven fortnightly $100 \mathrm{~mm}$ artificial rainfall events starting on 19 April and concluding on 4 June 2016.

- Seven artificial rainfall events of varying intensity, roughly at fortnightly intervals commencing 1 October 2016 and concluding on 27 December 2016.

From 4 June 2016 to 1 October 2016 (four months), the columns were allowed to dry out with no artificial rainfall added.

In total 1,450 $\mathrm{mm}$ of artificial rainfall was added to the columns, equivalent to approximately three times the annual rainfall of $400 \mathrm{~mm}$. 


\subsubsection{Mine B}

The column trials at Mine B were subjected to eight artificial rainfall events over approximately four months-that is, eight roughly fortnightly $60 \mathrm{~mm}$ artificial rainfall events starting on 24 January and concluding on 5 May 2018.

In total $480 \mathrm{~mm}$ of artificial rainfall was added to the columns, equivalent to approximately one year of annual rainfall (approximately $400 \mathrm{~mm}$ ).

\subsection{Stored infiltration}

Stored infiltration in the covers can be calculated on a daily basis by multiplying the change in volumetric water content by depth. The daily incremental change in stored infiltration balances the infiltration budget on a daily basis as either wetting or drying. As such, it is proportional to the rate of evaporation. Figure 4 presents the stored infiltration in the column trials versus time. Figure 5 shows that as cover thickness increases, so too does its ability to store artificial rainfall:

- The $0.45 \mathrm{~m}$ cover at Mine A can store a maximum of $24 \mathrm{~mm}$ of artificial rainfall or $24 \%$ of a $100 \mathrm{~mm}$ artificial rainfall event.

- The $0.6 \mathrm{~m}$ cover at Mine A can store a maximum of $32 \mathrm{~mm}$ of artificial rainfall or $32 \%$ of a $100 \mathrm{~mm}$ artificial rainfall event.

- The $0.8 \mathrm{~m}$ cover at Mine A can store a maximum of $50 \mathrm{~mm}$ of artificial rainfall or $50 \%$ of a $100 \mathrm{~mm}$ artificial rainfall event.

- The $0.2 \mathrm{~m}$ cover at Mine B can store a maximum of $6 \mathrm{~mm}$ of artificial rainfall or $6 \%$ of a $100 \mathrm{~mm}$ artificial rainfall event.

- The $0.4 \mathrm{~m}$ cover at Mine B can store a maximum of $10 \mathrm{~mm}$ of artificial rainfall or $10 \%$ of a $100 \mathrm{~mm}$ rainfall event.

- The $0.6 \mathrm{~m}$ cover at Mine B can store a maximum of $18 \mathrm{~mm}$ of artificial rainfall or $18 \%$ of a $100 \mathrm{~mm}$ rainfall event.

\subsection{Seepage}

Figure 6 presents the measured seepage (from the rain gauge tipping buckets) for the covers at Mine $A$ and Mine B:

- The maximum seepage from the $0.45 \mathrm{~m}$ cover at Mine A was $19 \%$ of cumulative artificial rainfall (139 mm).

- The maximum seepage from the $0.6 \mathrm{~m}$ cover at Mine A was $17 \%$ of cumulative artificial rainfall (125 mm).

- The maximum seepage from the $0.8 \mathrm{~m}$ cover at Mine A was $23 \%$ of cumulative artificial rainfall (169 mm).

- The maximum seepage from the $0.2 \mathrm{~m}$ cover at Mine B was $6 \%$ of cumulative artificial rainfall $(28.8 \mathrm{~mm})$.

- The maximum seepage from the $0.4 \mathrm{~m}$ cover at Mine B was $1 \%$ of cumulative artificial rainfall $(4.8 \mathrm{~mm})$.

- The maximum seepage from the $0.6 \mathrm{~m}$ cover at Mine B was $1 \%$ of cumulative artificial rainfall $(4.8 \mathrm{~mm})$. 


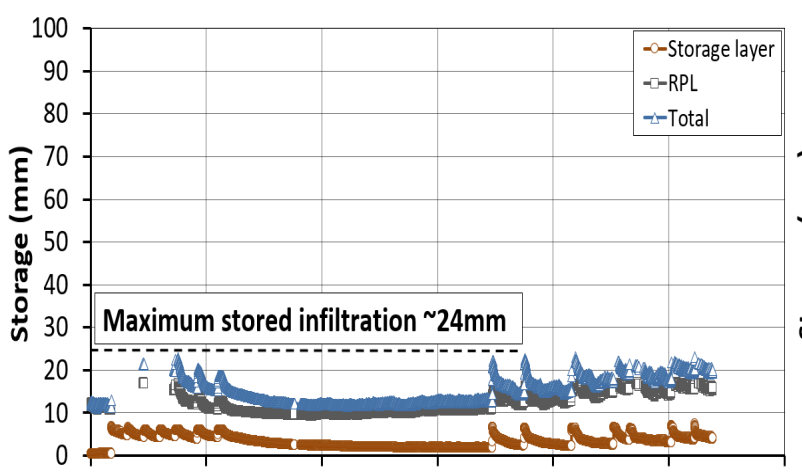

(a)

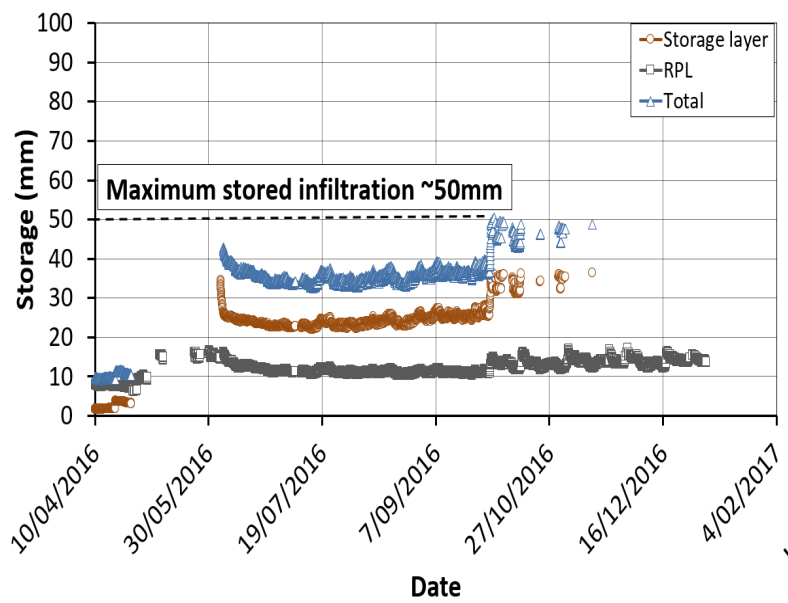

(c)

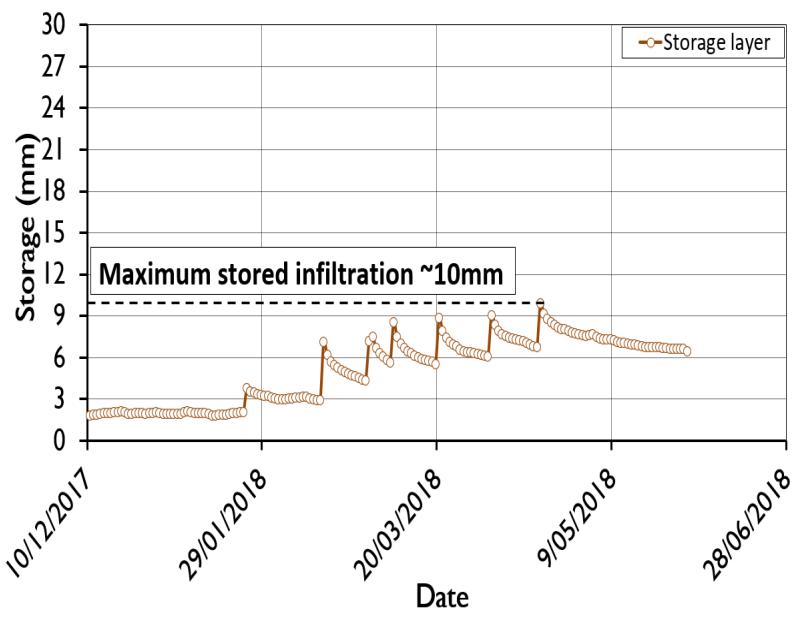

(e)

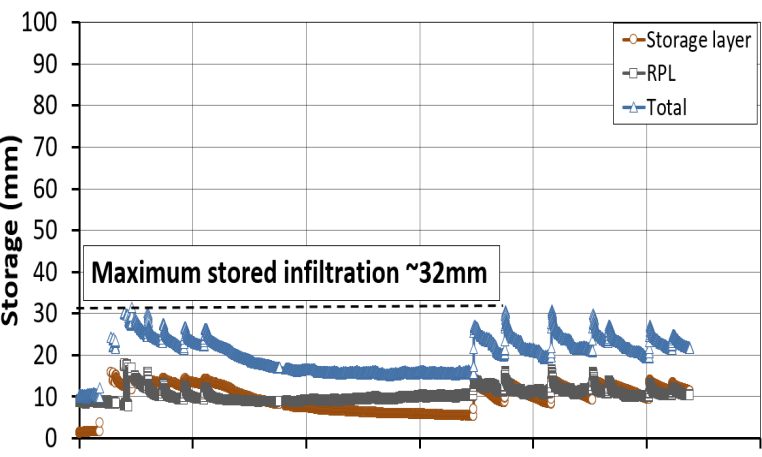

(b)

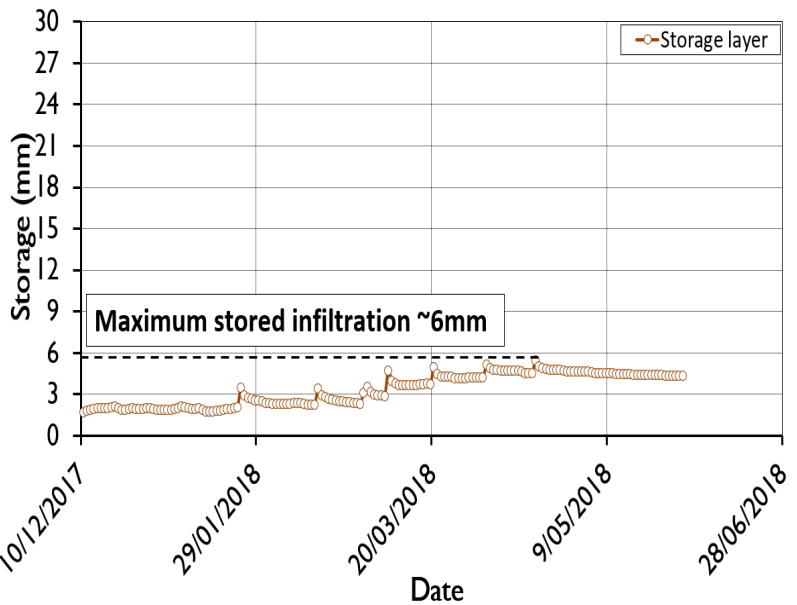

(d)

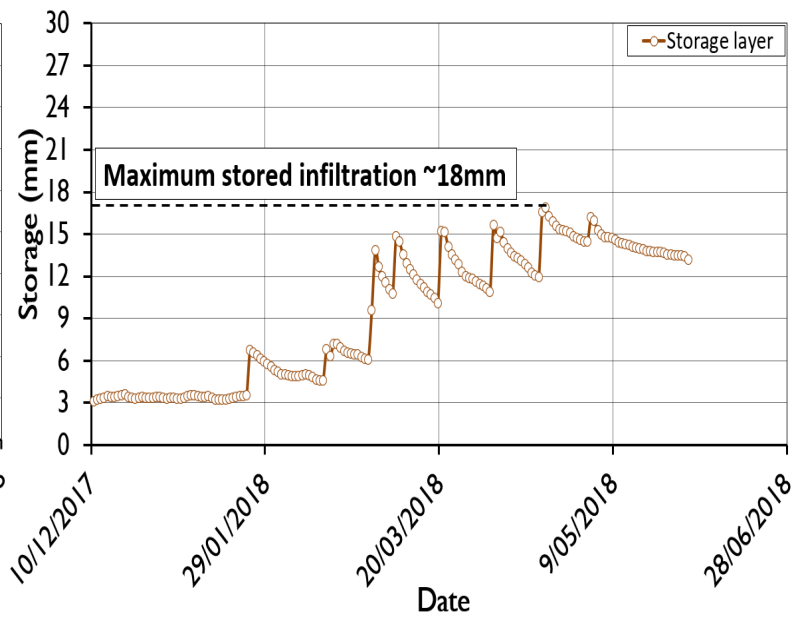

(f)

Figure 5 Stored infiltration: (a) $0.45 \mathrm{~m}$ cover (Mine A); (b) $0.6 \mathrm{~m}$ cover (Mine A); (c) $0.8 \mathrm{~m}$ cover (Mine A); (d) $0.2 \mathrm{~m}$ cover (Mine B); (e) $0.4 \mathrm{~m}$ cover (Mine B); (f) $0.6 \mathrm{~m}$ cover (Mine B) 


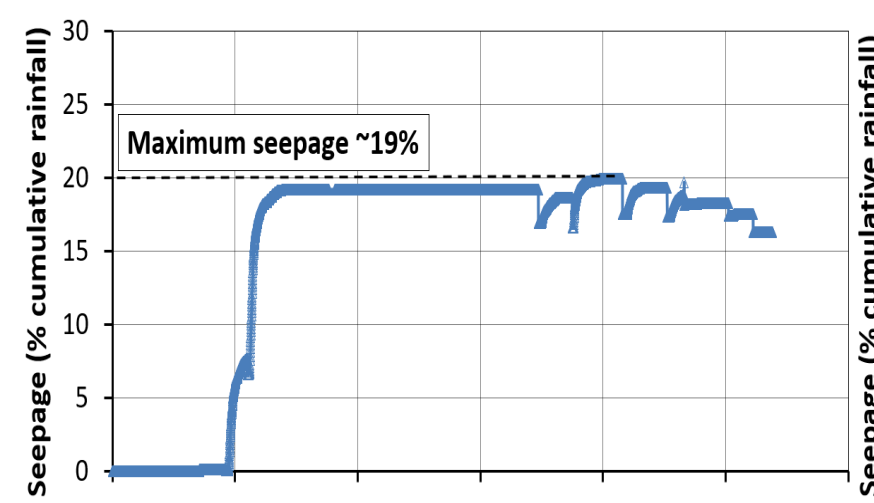

(a)
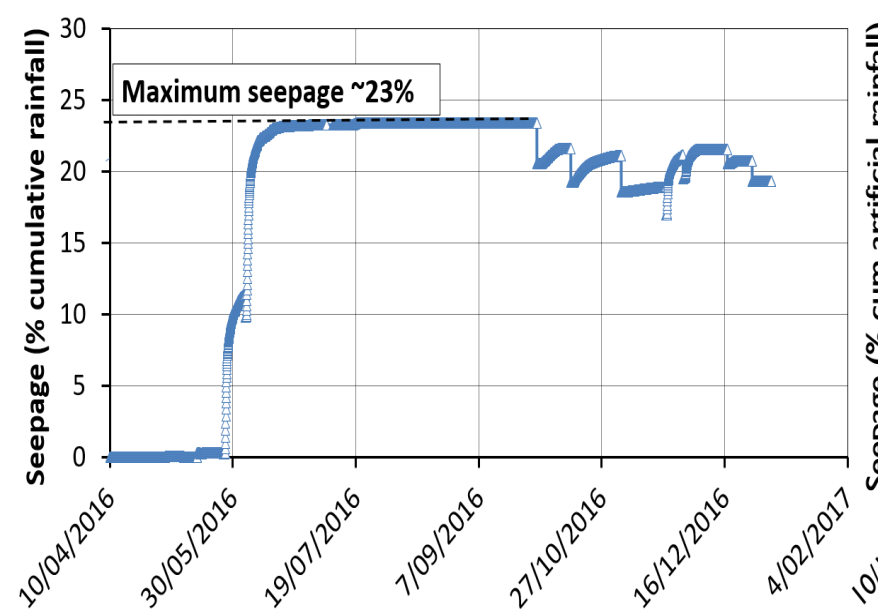

Date

(c)

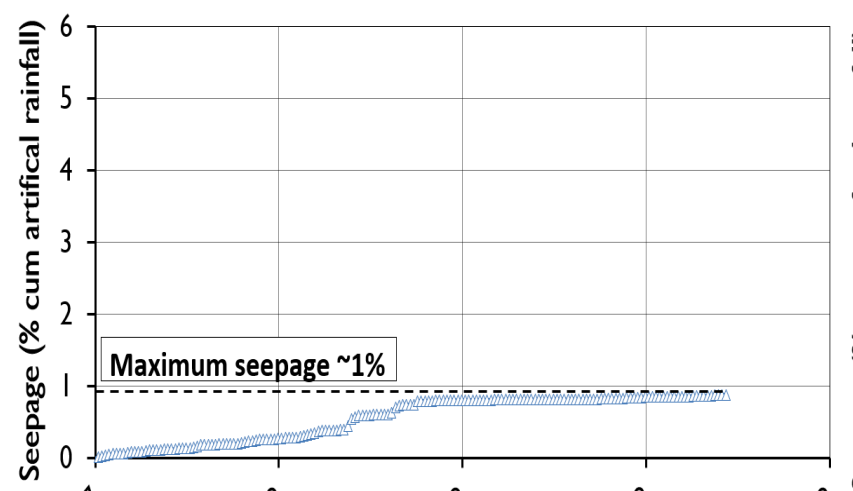

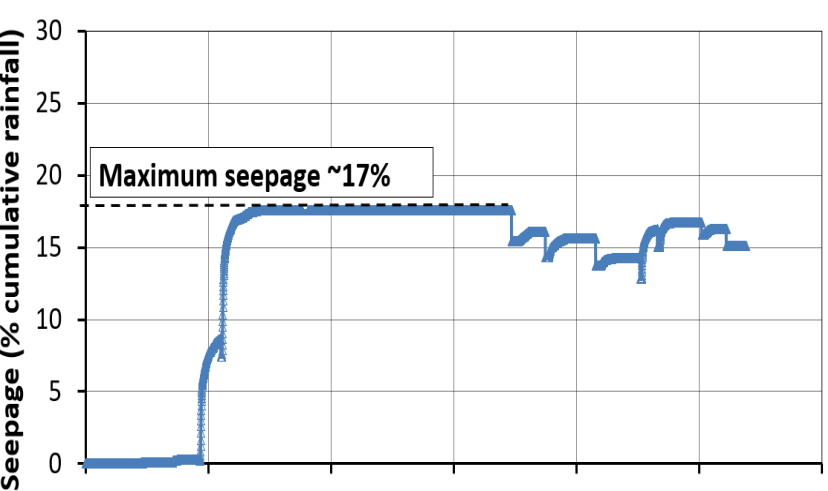

(b)

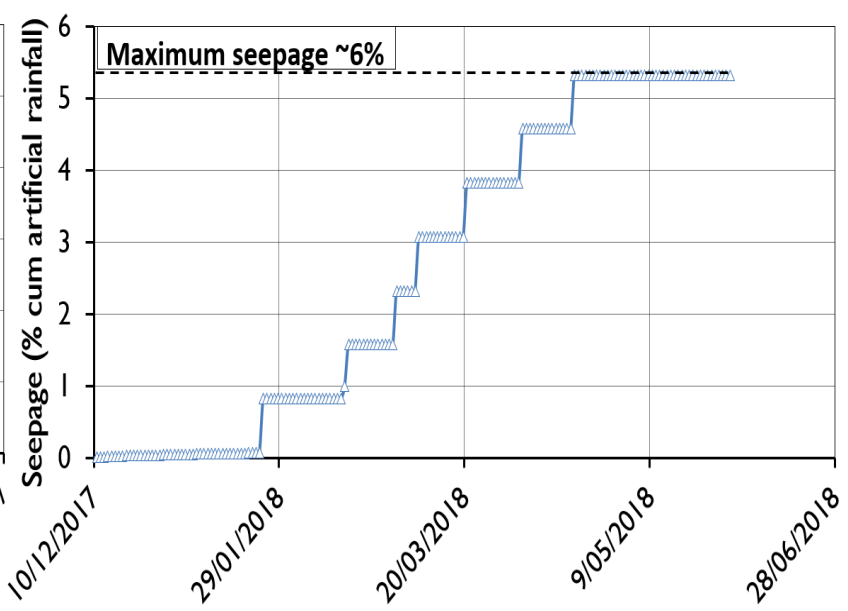

Date

(d)

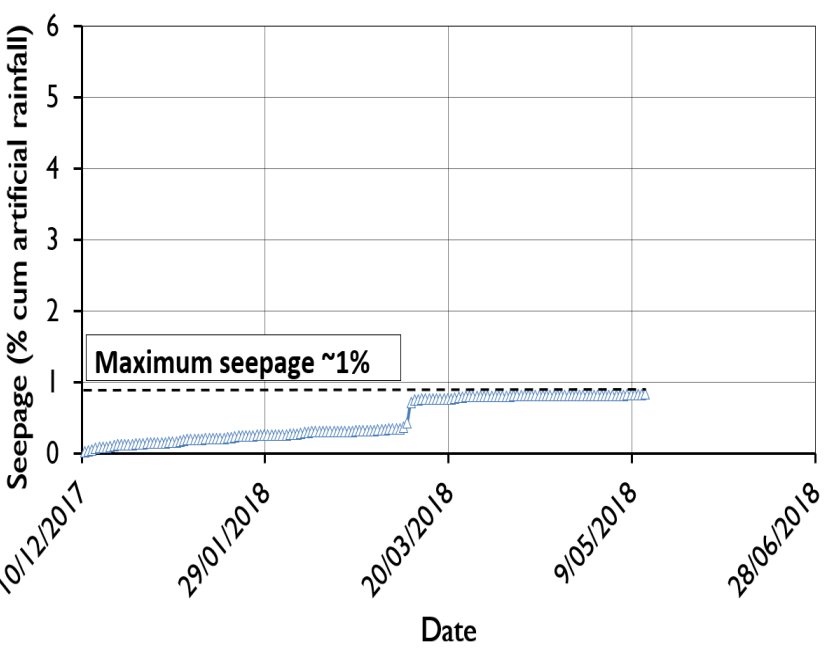

(f)

Figure 6 Seepage: (a) $0.45 \mathrm{~m}$ cover (Mine A); (b) $0.6 \mathrm{~m}$ cover (Mine A); (c) $0.8 \mathrm{~m}$ cover (Mine A); (d) $0.2 \mathrm{~m}$ cover (Mine B); (e) $0.4 \mathrm{~m}$ cover (Mine B); (f) $0.6 \mathrm{~m}$ cover (Mine B) 


\subsection{Water balance}

Incorporating artificial rainfall, stored infiltration results and seepage allows for the calculation of a water balance (Table 1), for each column trial by solving for evaporation using Equation 1.

Table 1 Water balance for each column trial (based on maximum stored infiltration)

\begin{tabular}{|llll}
\hline Cover thickness & $\begin{array}{l}\text { Water balance } \\
\text { element }\end{array}$ & Flux (mm) & $\begin{array}{l}\text { Flux (\% of cumulative } \\
\text { artificial rainfall) }\end{array}$ \\
\hline $0.45 \mathrm{~m}$ (Mine A) & Stored infiltration & 24 & 3 \\
& Seepage & 139 & 19 \\
& Evaporation & 562 & 78 \\
\hline $0.6 \mathrm{~m}$ (Mine A) & Stored infiltration & 32 & 4 \\
& Seepage & 125 & 17 \\
& Evaporation & 568 & 78 \\
\hline \multirow{2}{*}{$0.8 \mathrm{~m}$ (Mine A) } & Stored infiltration & 50 & 7 \\
& Seepage & 169 & 23 \\
& Evaporation & 506 & 70 \\
\hline $0.2 \mathrm{~m}$ (Mine B) & Stored infiltration & 6 & 1.3 \\
& Seepage & 28.8 & 6.0 \\
& Evaporation & 445.2 & 92.8 \\
& Stored infiltration & 10 & 2.1 \\
\hline $0.4 \mathrm{~m}$ (Mine B) & Seepage & 4.8 & 1.0 \\
& Evaporation & 465.2 & 96.9 \\
\hline $0.6 \mathrm{~m}$ (Mine B) & Stored infiltration & 18 & 3.8 \\
& Seepage & 4.8 & 1 \\
& Evaporation & 457.2 & 95.3 \\
\hline
\end{tabular}

The column trials have shown (Table 1):

- Evaporation rate for regional covers varies from 70-96.9\% noting that the Mine A cover column trials ran over a longer period of time and incorporated times of the year with a lower evaporation rate (i.e. winter).

- If the cover thickness is too thin then there is insufficient infiltration storage capacity, resulting in more rapid development of near saturated conditions correlating to an increase in the seepage potential.

- If the cover is too thick, rainfall may infiltrate deep enough that the effect of evaporation decreases. This can result in the development of near saturated conditions at the base of the infiltration storage layer, correlating to an increase in the seepage potential (e.g. $0.8 \mathrm{~m}$ Mine A cover).

- The preferred cover options (the preferred covers) provide the best balance between infiltration storage and evaporation effect resulting in the lowest recorded seepage:

- The $0.6 \mathrm{~m}$ (Mine A) cover that is made up of $0.3 \mathrm{~m} \mathrm{RPL}$ and $0.3 \mathrm{~m}$ infiltration storage layer of soil.

- The $0.6 \mathrm{~m}$ (Mine B) cover made up solely of an infiltration storage layer of soil. 
EC monitoring of the cover trials indicated that significant capillary rise of metals and salts from the accretion and/or tailings to the overlying soil is not occurring in both the Mine A and Mine B columns.

It is important to note that the results presented represent a worst-case scenario, and it is expected that the preferred covers will perform better at a field scale, since the covers will be vegetated and the region is located in a semi-arid environment, resulting in a highly unsaturated cover for most of the year.

\section{Discussion}

\subsection{Model results}

Figure 7 shows the results of the model volumetric water content prediction compared to the in situ results for the $0.6 \mathrm{~m}$ (Mine B) cover. It is noticeable that the model prediction closely matches the magnitude of response measured in the cover column trial.

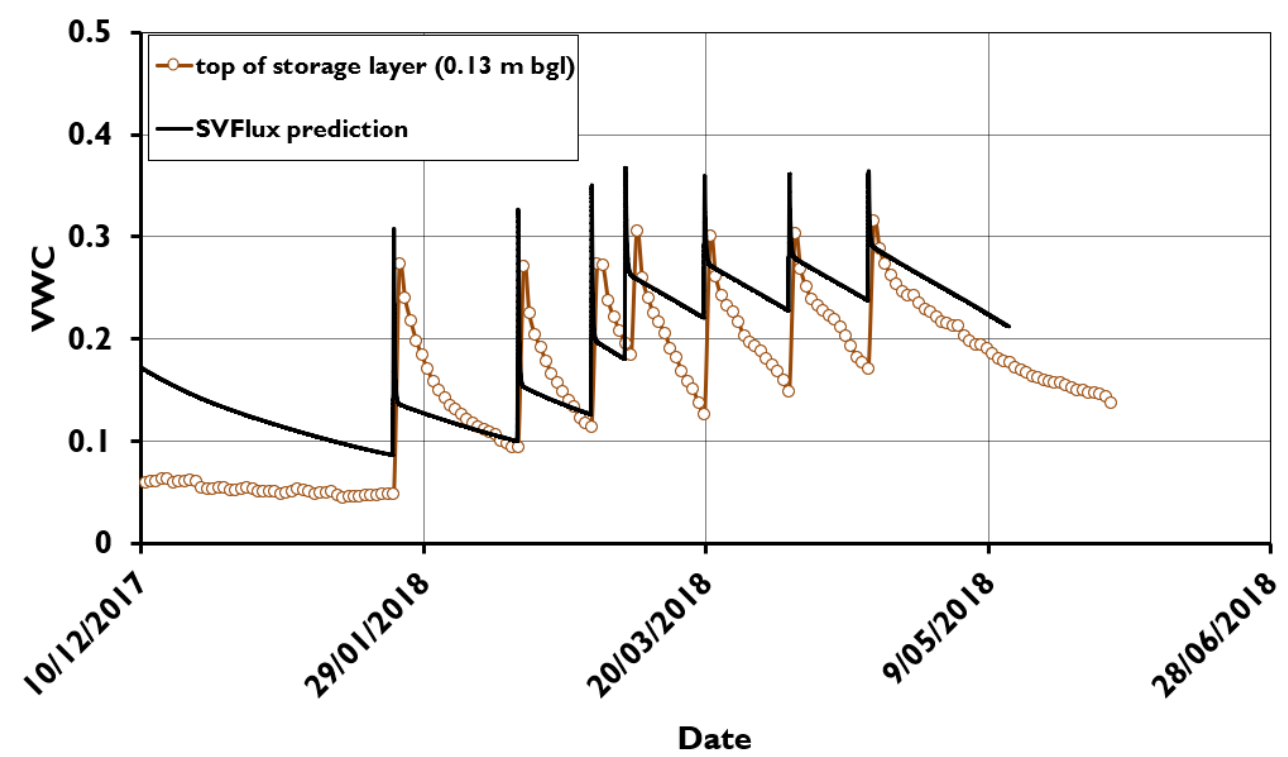

Figure 7 Model results compared to the $0.6 \mathrm{~m}$ (Mine B) cover column trial

The models validated the initial conditions described in Section 3.3.3 and provides actual evaporation results using the Modified Wilson Empirical Equation (Wilson et al. 1997) that is presented in Section 5.1.1.

\subsubsection{Water balance}

A comparison of the artificial water balance from the $0.6 \mathrm{~m}$ (Mine $\mathrm{B}$ ) cover to the model is presented in Table 2. The comparison shows that the semi-calibrated model shows a reasonable correlation between the predicted and observed seepage, it is less accurate in predicting evaporation and stored infiltration.

Table 2 Water balance comparison between $0.6 \mathrm{~m}$ cover (Mine B) and the model

\begin{tabular}{lll}
\hline Water balance element & Column & Model \\
\hline Rainfall (mm) & 480 & 480 \\
Stored infiltration (\%) & 3.8 & 8.5 \\
Seepage (\%) & 1.0 & 0.5 \\
Evaporation (\%) & 95.3 & 90 \\
\hline
\end{tabular}


The inconsistency of the results is likely to do with the SWCCs. That is, the model accuracy would likely improve by further segregation of the SWCCs presented in Figure 6. Further, the model cannot account for macro-pore infiltration flow in response to short duration, high intensity rainfall that may result in bypass flow-through the cover column trials.

\subsubsection{Future cover performance}

The performance of both preferred covers is shown for an average, wet and dry year and is presented in Table 3.

Table 3 Summary of $0.6 \mathrm{~m}$ cover (Mine A) and $0.6 \mathrm{~m}$ cover (Mine B) performance for average, wet and dry years

\begin{tabular}{lllll}
\hline Cover thickness & Water balance element & Dry year & Average year & Wet year \\
\hline $0.6 \mathrm{~m}$ (Mine A) & Rainfall $(\mathrm{mm})$ & 101.6 & 358.2 & 806.5 \\
& Seepage $(\%)$ & 0.1 & 0.7 & 1 \\
\hline \multirow{2}{*}{$0.6 \mathrm{~m}$ (Mine B) } & Rainfall $(\mathrm{mm})$ & 101.6 & 358.2 & 806.5 \\
& Seepage (\%) & 0.16 & 0.3 & 0.44 \\
\hline
\end{tabular}

Table 3 shows that the two preferred cover options had similar performance.

\section{Conclusion}

This paper examined the cover design process for TSFs containing PAF tailings at Mine A and Mine B that are located in the Cobar region and share similar geology, soils, land uses and climate. Therefore, the cover design process implemented was similar.

Column trials have been run for three cover thicknesses at Mine A and Mine B and have resulted in a maximum probable water balance for each cover. The results indicate that the $0.6 \mathrm{~m}$ cover trialled at Mine $A$ and the $0.6 \mathrm{~m}$ cover trialled at Mine B are suitable cover designs for TSFs in the region. SVFlux models of the two preferred covers showed good correlation to the observed results and it was accepted that the semicalibrated model could be used to predict the long-term performance of the covers. Seepage was predicted to be under $1 \%$ in the long-term indicating limited potential for the transport of AMD.

A suitable TSF cover in the region can therefore contain a $0.6 \mathrm{~m}$ infiltration storage layer of soil or, stockpiled soil can be supplemented by using a $0.3 \mathrm{~m}$ infiltration storage layer of soil underlain by a $0.3 \mathrm{~m} \mathrm{RPL}$. These covers provide a suitable balance between infiltration storage and evaporation effect resulting in low seepage. The results presented represent a worst-case scenario, and it is expected that these cover options will perform better at a field scale, since the covers will be vegetated and the region is in a semi-arid environment, resulting in a highly unsaturated cover for most of the year.

\section{References}

Fredlund, DG \& Xing, A 1994, 'Equations for the soil water characteristic curve', Canadian Geotechnical Journal, vol. 31, no. 3, pp. 521-532.

International Network for Acid Prevention 2009, Global Acid Rock Drainage Guide, viewed 10 March 2019, www.gardguide.com National Environment Protection Council 2013, National Environment Protection (Assessment of Site Contamination) Measure, Adelaide, viewed 10 March 2019, http://www.nepc.gov.au/nepms/assessment-site-contamination

SoilVision 2009, Introducing SVFlux, Saskatoon, viewed 10 March 2019, www.soilvision.com/products/svoffice-ge/svflux-ge

Wilson, GW, Fredlund, DG \& Barbour, SL 1997, 'The effect of soil suction on evaporative fluxes from soil surfaces', Canadian Geotechnical Journal, vol. 34, no. 4, pp. 145-155. 
